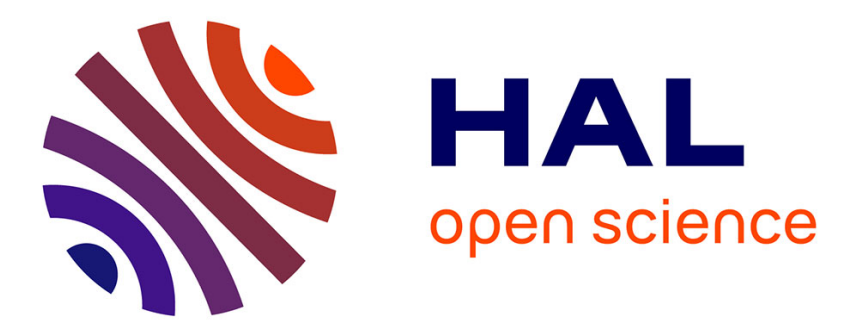

\title{
Agglomeration of Metals During Pyrolysis of Chromated Copper Arsenate (CCA) Treated Wood Waste
}

\author{
Mohammed Kemiha, Ange Nzihou, David Mateos
}

\section{To cite this version:}

Mohammed Kemiha, Ange Nzihou, David Mateos. Agglomeration of Metals During Pyrolysis of Chromated Copper Arsenate (CCA) Treated Wood Waste. High-temperature materials and processes, 2008, 27 (5), p.361-368. 10.1515/HTMP.2008.27.5.361 . hal-01634034

\section{HAL Id: hal-01634034 \\ https://hal.science/hal-01634034}

Submitted on 31 Oct 2019

HAL is a multi-disciplinary open access archive for the deposit and dissemination of scientific research documents, whether they are published or not. The documents may come from teaching and research institutions in France or abroad, or from public or private research centers.
L'archive ouverte pluridisciplinaire HAL, est destinée au dépôt et à la diffusion de documents scientifiques de niveau recherche, publiés ou non, émanant des établissements d'enseignement et de recherche français ou étrangers, des laboratoires publics ou privés. 


\title{
Agglomeration of Metals During Pyrolysis of Chromated Copper Arsenate (CCA) Treated Wood Waste
}

\author{
Mohammed Kemiha ${ }^{a^{*}}$, Ange Nzihou ${ }^{a}$ and David Mateos ${ }^{b}$ \\ ${ }^{a}$ Centre RAPSODEE, UMR-CNRS 2392, \\ Ecole des Mines d'Albi-Carmaux, Campus Jarlard, 81000 Albi, France \\ ' Thermya Company, \\ 1 rue Nicolas Appert, 33140 Villenave d'Ornon, France \\ *corresponding author: mohammed.kemiha(a)mines-albi.fr. Tel : +33563493249, Fax: +33563493243
}

(Received December 20, 2008)

\begin{abstract}
The number of waste disposal sites decreases and redundant poles, piling and lumber, which constitute a large volume of material, may not be accepted at the limited number of sites in the future. CCA contaminated wood contains around $1-5 \%$ of metal in form of arsenic pentoxide, hexavalent and trivalent chromium compounds and copper sulfate, which act as fungicides and insecticides throughout the life of the wood. While CCA treatment is gradually becoming a banned practice, approximately 4 million tonnes of CCA treated wood is generated in the EU per year, which is set to continue for many decades as the in-service wood is generated in end of its life. Recycling wood waste is important for the effective utilization of natural resources. The charcoal product resulting from CCA treated wood contains $\mathrm{Cu}, \mathrm{Cr}$ and As. The metals appear as both agglomerates and diffused in the solid matrix. Moreover, during pyrolysis an agglomeration process takes place, which induces not only the growth of existing mineral agglomerates but also the formation of new agglomerates. The objective of the present work is the valorisation of CCA metals and charcoal from treated wood waste. The research aims at understanding and promoting experimentally, at different pyrolysis heating rates, the generation of charcoal with high specific surface area from pyrolysed treated wood waste.
\end{abstract}

Keywords: CCA wood waste, pyrolysis, specific surface area, agglomeration, heavy metals.

\section{INTRODUCTION}

Telephone poles, railway sleepers, timber from landscape and cooling towers, wooden silos, hop-poles, cable drums and wooden play-ground equipment gerketate waste for which environmentally benign technologies need to be developed. The main part of the wood waste is the chromated copper arsenate (CCA-) treated one $/ 1 /$. The number of waste disposal sites decreases and redundant poles, piling and lumber, which constitute a large volume of material, may not be accepted at the limited number of sites in the future. So, recycling wood waste is important for the effective utilization of natural resources $/ 2 /$.

It is beneficial to utilize the energy resources of the impregnated wood waste thermal treatment. Meanwhile, thermal treatment must be done with caution to avoid emission of toxic compounds to the surrounding environment, especially when dealing with wood waste containing arsenic $/ 3 /$.

The disposal of CCA-treated waste woods has become a serious environmental problem all over the world. The existing and emerging technologies for managing CCA-treated wood waste include: recycling and recovery, chemical extraction, bioremediation, electrodialytic and thermal destruction $/ 4 /$. 
Thermal degradation process seems to be a promising technology for material and energy recovery from CCA treated waste wood. Material recovery is based on the formation of clusters or agglomerates, consisting in metals and minerals, during thermal degradation of CCA-treated wood $15 \%$. The characterization using a scanning electron microscopy coupled with energy dispersive X-ray analysis (ESEM-EDS) has shown that the metal compounds form agglomerates during pyrolysis, thus suggesting that the metals can be easily recovered from the charcoal in a dry way $/ 6,7 /$.

To dispose of chromated copper arsenate (CCA) treated waste wood, Thermya Company has developed the so-called "Chartherm" process, a novel low temperature thermal process in which "chartherisation" is the thermal part. Practically, this process consists in a staged pyrolytic distillation /8/.

During the chartherisation process, crushed wood is loaded in a reaction column where it is permanently submitted to a flow of neutral gas. The neutral hot gas (low oxygen content, $370^{\circ} \mathrm{C}$ ), coming from a heat generator, is injected at the bottom of this reaction column. An increasing stratified gradient of pressures and temperatures is obtained by controlling the pressure drop between the top and the bottom of the column in order to always maintain the temperature at the top of the column below $65^{\circ} \mathrm{C}$. Therefore, the chartherisation process is quite similar to a distillation process: the wood waste, introduced at the upper part of the column, gradually loses all its water and organic matter as it goes down. Finally, its mineral part is the only one remaining at the bottom of the column. In fact, most of the mineral part $(>97 \%)$ is carbon, which was the wood matrix.

At the bottom of the column, the thermal choc between the hot gas and the wood breaks the hydrogen bonds, which liberates groups of organic molecules and causes their evaporation from the wood. This mixture of gases and vapours of organic molecules is pushed up through the bed, where it is cooled down and condensed by the crushed wood.

The crushed wood particles heat up during their descent in the bed, and the organic molecules, condensed on the wood particles, crack and evaporate, then condense again at a higher level in the column. This phenomenon is repeated until the organics become light enough and their condensation point low enough (below $65^{\circ} \mathrm{C}$ ), that they do not condense any more and they make their way to the top of the column. The process is thus characterized by a sequence of evaporation, cooling, condensation, heating, cracking phenomena... where the bed of wood particles acts both as a condenser and a filter.

The charcoal residue extracted from the bottom of the column is cooled, milled to powder and introduced into a pneumatic centrifuge. Centrifugal separation results in a clean carbon product on one side and a powder containing all other minerals (including all metals) on the other side.

The charcoal product resulting from CCA-treated wood contains $\mathrm{Cu}, \mathrm{Cr}$ and As. The metals appear as both agglomerates and diffused in the solid matrix. So, an agglomeration process takes place during pyrolysis, which induces not only the growth of existing mineral agglomerates but also the formation of new agglomerates $/ 5 /$.

The objective of the present work is the valorisation of CCA metals and charcoal from treated wood waste. The research aims at understanding and promoting experimentally the generation of charcoal with high specific surface area from pyrolysed treated wood waste.

\section{MATERIALS AND METHODS}

\subsection{Wood samples}

Two batches of wood waste samples were obtained from Thermya Company: wood waste and CCA-treated wood. Wood waste samples are those obtained from recuperating telephone poles and railway sleepers, etc. CCA-treated wood samples are obtained by impregnation of wood in a preservative CCA solution.

The samples were broken into chips with a size smaller than $2 \mathrm{~mm}$ and mixed in order to obtain homogeneous samples.

The metal content of the samples has been determined using ICP-AES after dissolution with aqua regia $\left(\mathrm{HCl} / \mathrm{HNO}_{3}\right)$ and $\mathrm{HF}$ as proposed in ASTEM's method (American Society for Testing and Materials) 19/. As can be seen in Table 1, the metals' 
concentrations in the CCA-treated wood samples are three to fourfold higher than in the wood waste samples.

Table 1

Metal ( $\mathrm{As}, \mathrm{Cr}$ and $\mathrm{Cu}$ ) concentrations ( $\mathrm{mg} / \mathrm{kg}$ of wood) of the CCA-treated wood and wood waste.

\begin{tabular}{|c|c|c|c|}
\hline Sample & As $(\mathrm{mg} / \mathrm{kg})$ & $\mathrm{Cr}(\mathrm{mg} / \mathrm{kg})$ & $\mathrm{Cu}(\mathrm{mg} / \mathrm{kg})$ \\
\hline $\begin{array}{c}\text { CCA- } \\
\text { treated } \\
\text { wood }\end{array}$ & 25770 & 32150 & 11520 \\
\hline $\begin{array}{c}\text { Wood } \\
\text { waste }\end{array}$ & 5890 & 7620 & 4120 \\
\hline
\end{tabular}

\subsection{Thermal characterization}

Differential scanning calorimetry (DSC) and Thermogravimetric analysis (TGA) are common techniques for measuring the heat flux and the weight changes of a material versus temperature and time. In this study, TGA and DSC were performed simultaneously in dynamic mode using a SETARAM TGA-DSC 111 analyzer. In each experiment, the wood sample, approximately $25 \mathrm{mg}$ in weight, was introduced into platinum sample pan and heated from room temperature up to $700^{\circ} \mathrm{C}$ at a heating rate of $5^{\circ} \mathrm{C} / \mathrm{min}$, under nitrogen inert atmosphere.

The thermal behaviour of the different samples (wood waste and CCA-treated wood) obtained by TGA) are compared in Fig. 1. These weight loss versus temperature curves evolve similarly, but at lower decomposition temperature for CCA-treated wood. The difference in decomposition temperature, corresponding to the temperature peak gap, is due to the catalytic effects of CCA metals $/ 10,11 /$. So, the arsenic, copper, and chromium compounds act as accelerators of the degradation of wood samples compounds. Finally, the TG curves are in agreement with those in literature $/ 10$, 121.

These curves point out three key stages: the volatile loss at low temperature, the main pyrolysis, and the carbonisation. In the early stage, water begins to volatilize and it is completely gone at $200^{\circ} \mathrm{C}$, this corresponds to the large endothermic peak in the heat flux curve. Most weight loss occurs in the main pyrolysis stage, which is observed between $200^{\circ} \mathrm{C}$ and $370^{\circ} \mathrm{C}$. This stage corresponds to the decomposition of hemicelluloses and cellulose compounds of wood. The endothermic peak between $300^{\circ} \mathrm{C}$ and $400^{\circ} \mathrm{C}$ in the heat flux curve is attributed to the cellulose decomposition. The carbonisation stage occurs at a temperature beyond $370^{\circ} \mathrm{C}$, corresponding to the lignin degradation and to the release of remaining volatiles from the solid pyrolysis product. Finally, at $700^{\circ} \mathrm{C}$ the char yield for inert pyrolysis is about $30 \%$ for CCA-treated wood and $24 \%$ for wood waste.

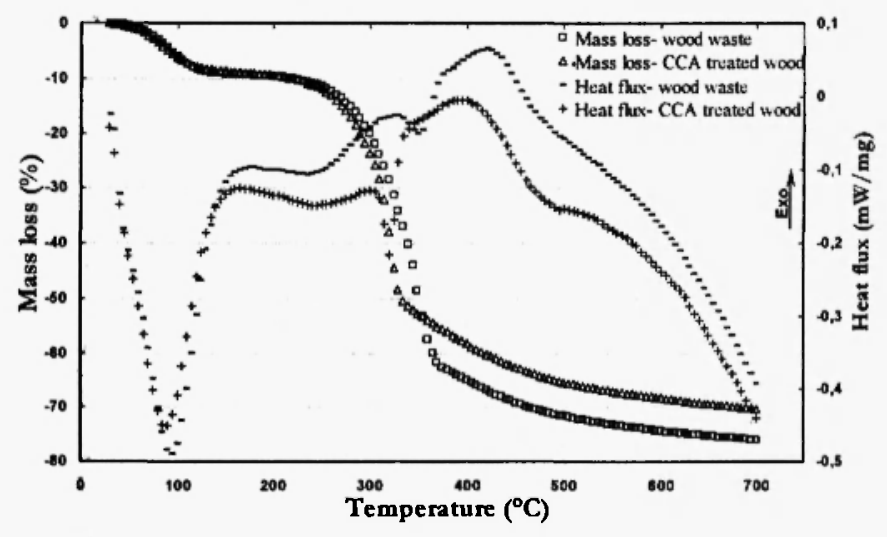

Fig. 1: Mass loss and heat flux versus temperature during pyrolysis of wood waste and CCAtreated wood, under nitrogen atmosphere and heating rate $5^{\circ} \mathrm{C} / \mathrm{min}$.

\subsection{Chemical analysis}

The amounts of arsenic, copper and chromium in the samples of waste wood, of CCA-treated wood and of pyrolysis residue were measured by inductively coupled plasma (ICP-AES) spectrometry, after complete dissolution of the samples by acid attack in aqua regia solution as proposed in ASTEM's method.

\subsection{Physical analysis}

The specific surface areas of the samples and of the pyrolysis solid products at different temperatures (between 200 and $400{ }^{\circ} \mathrm{C}$ ) were determined using nitrogen adsorption with the BET method (MICROMERITRICS Gemini VacPrep 061). The 
samples were examined by environmental scanning electron microscopy (XL 30 ESEM-FEG, FIE Company).

\subsection{Pyrolysis procedure}

Pyrolysis experiments were carried out in a horizontal tubular furnace CARBOLITE 12/65/600 (diameter $=60 \mathrm{~mm}$, length $=600 \mathrm{~mm}$ ). A few grams of waste sample $(4-5 \mathrm{~g})$ are set in an alumina crucible and introduced into a quartz tube in a preheated furnace, under inert gas $\left(\mathrm{N}_{2}\right)$, with flow rate set at $100 \mathrm{NL} / \mathrm{h}$ (Fig. 2). The gas outlet is connected to a cascade of two impingers filled with a $100 \mathrm{~mL}$ solution of $0.5 \mathrm{M} \mathrm{HNO}_{3}$ for collecting the vaporized fraction of the heavy metals, thus used as cleaning gas system. Pyrolysis solid residues were analysed at the end of the experiment.

The influence of temperature on the agglomeration and on the metals' release during pyrolysis of wood wastes and CCA-treated wood was studied by carrying out experiments at $200^{\circ} \mathrm{C}, 320^{\circ} \mathrm{C}, 350^{\circ} \mathrm{C}, 370^{\circ} \mathrm{C}$, and $400^{\circ} \mathrm{C}$. These temperatures were chosen according to the TG curves obtained in the thermogravimetric study. The waste samples were heated from ambient temperature to the preset temperature at $20^{\circ} \mathrm{C} / \mathrm{min}$ for fast heating and at $5^{\circ} \mathrm{C} / \mathrm{min}$ for slow heating, then maintained at the preset temperature during 90 minutes (pyrolysis duration).

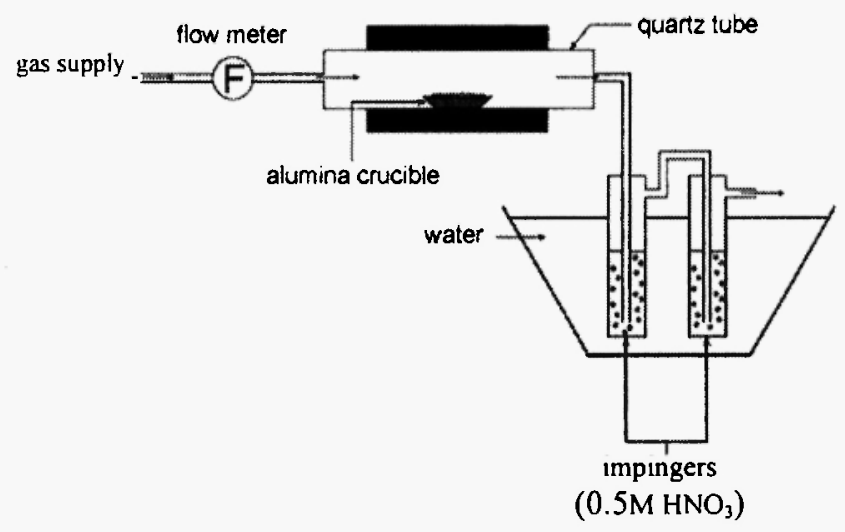

Fig. 2: Experimental set-up for pyrolysis study.

\section{RESULTS}

All pyrolysis residues obtained at different temperatures between 200 and $400^{\circ} \mathrm{C}$ and at two heating rates were analysed to determine their physical and chemical properties. A metals' redistribution within the wood is expected under the pyrolysis thermal effect. Indeed, wood compounds such as cellulose and hemicellulose are decomposed during pyrolysis, and therefore the metals bound to them during the impregnation process have to move to other locations $16 /$.

\subsection{ESEM Image analysis}

Environmental Scanning Electronic Microscopy (ESEM) with X-ray microanalysis has been applied to study the morphology and the chemical components of the pyrolysis residues. In the case of pyrolysis residues of CCA-treated wood, the charcoal keeps a wood structure during pyrolysis (Fig. 3). The CCA precipitated metals (As, $\mathrm{Cr}$ and $\mathrm{Cu}$ ) were detected as white spots (contrast) at the charcoal surface. The EDS analyses of the white spots identified arsenic, chromium and copper as the major metallic components. The pyrolysed CCA-treated wood has a structure similar to that of the wood waste, but with more metallic precipitates and agglomerates at its surface. The CCA metals' concentration increases with the pyrolysis temperature. In contrast, the metal content of residues from CCA-treated wood pyrolysed at $400^{\circ} \mathrm{C}$ is much higher than that obtained at lower temperature. The high initial metallic concentration in the case of CCA-treated wood explains mainly the abundance of $\mathrm{Cr}, \mathrm{Cu}$ and $\mathrm{As}$ in the pyrolysis products $/ 5 /$.

\subsection{Metals' concentrations}

The metallic concentrations in the pyrolysis solid residues were obtained by ICP-AES after acid-attack dissolution. In order to study both temperature and heating rate effects on the CCA metals stability, Fig. 4 summarizes the results by showing the metals' concentrations over the range of experimental 

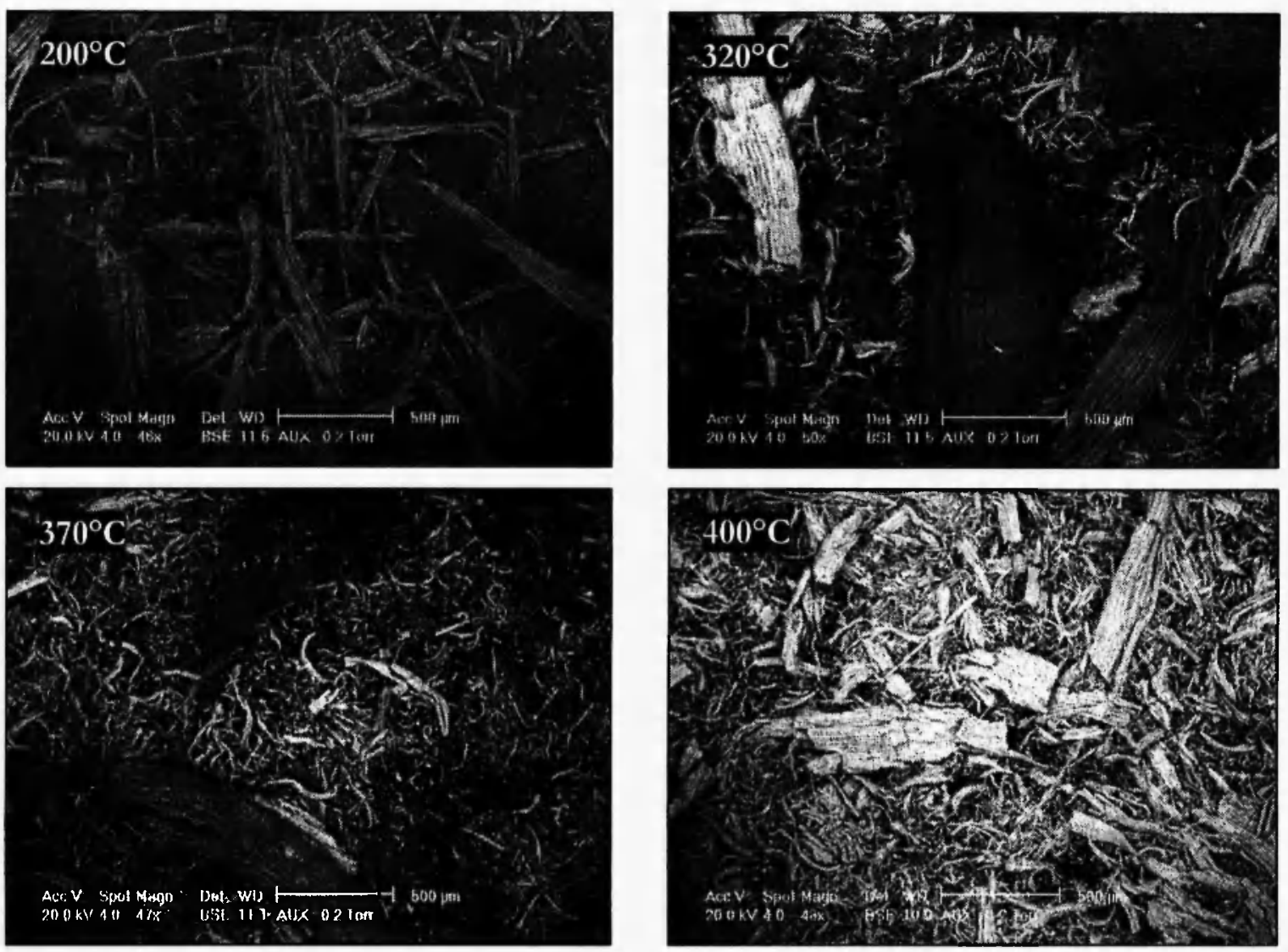

Fig. 3: Environmental scanning electronic micrographs (ESEM) of CCA treated wood residues at different pyrolysis temperatures (heating rate $=20^{\circ} \mathrm{C} / \mathrm{min}$ and pyrolysis duration $=90 \mathrm{~min}$ ).

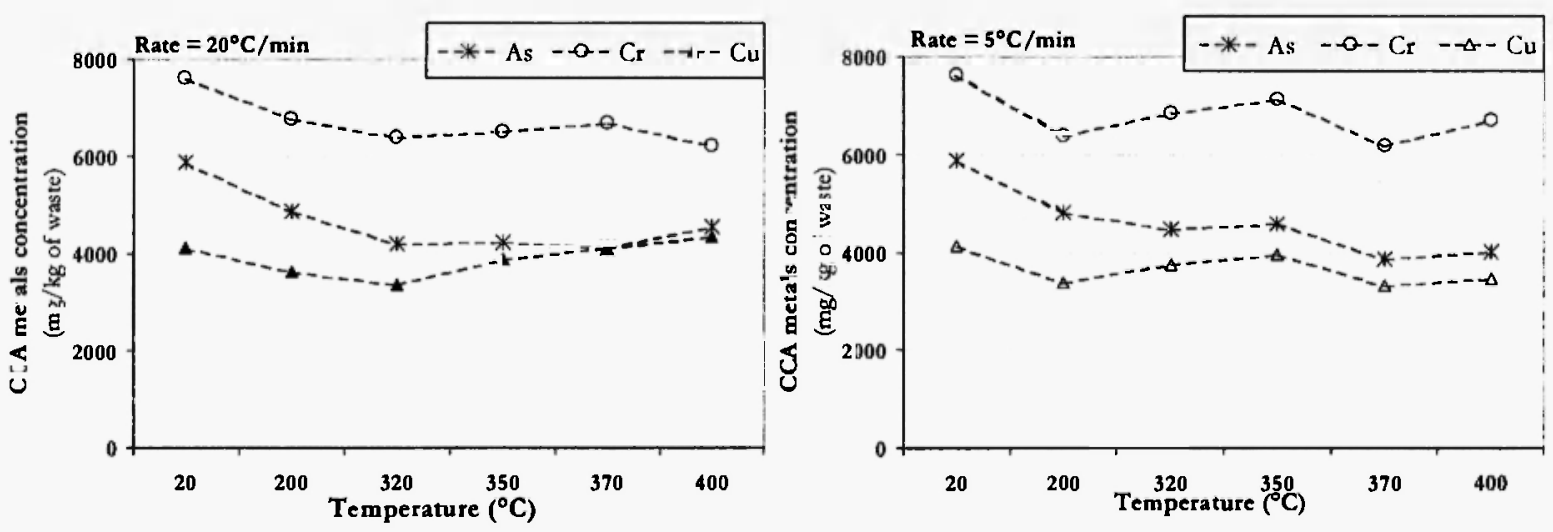

(a) Wood waste

Fig. 4(a): Wood Waste 

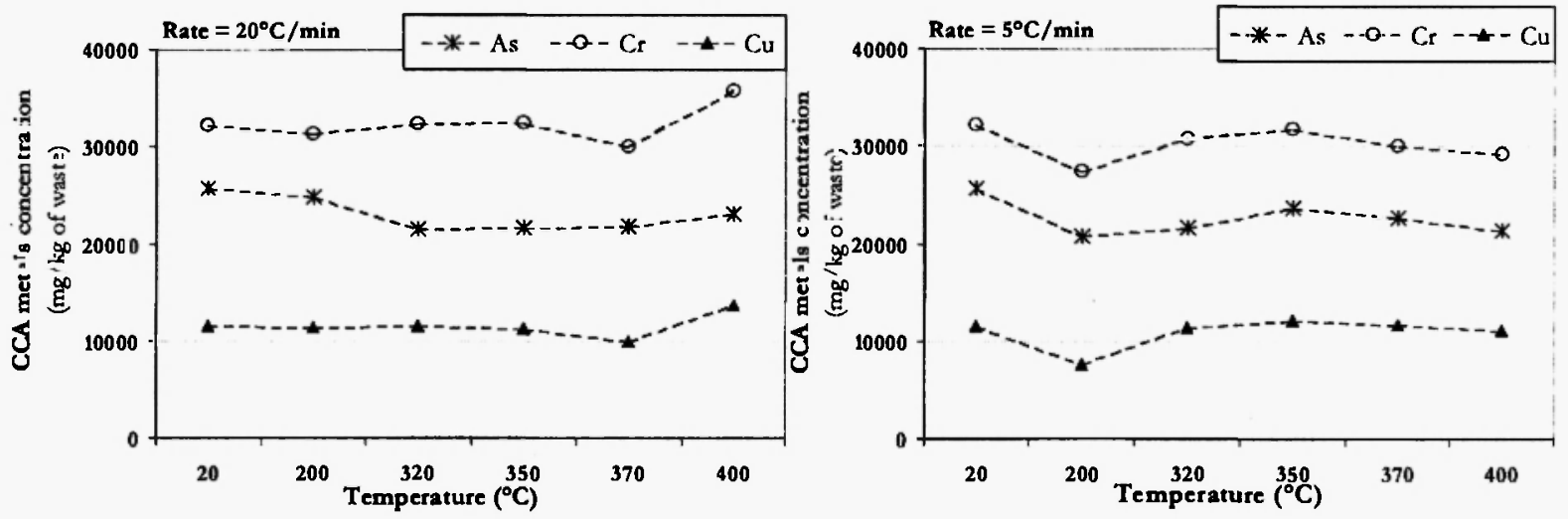

(b) CCA-treated wood

Fig. 4(b): CCA-treated wood

Fig. 4: Concentrations of CCA metals in solid residues at different temperatures and two heating rates.

conditions for both wood waste and CCA-treated wood samples, starting from the initial concentrations (at $20^{\circ} \mathrm{C}$ ). The decreasing of metal amounts comes from the volatilisation of CCA compounds during pyrolysis. The measurements uncertainties are less then $5 \%$ for CCAtreated wood and about $9 \%$ for wood waste. These uncertainties are very acceptable because the samples are wastes of different kinds, particularly, for wood waste sample. Fig. 4 shows that for wood waste, the amount of copper is essentially stable in the system whatever the temperature and the heating rate. The copper present in the solid residues of pyrolysis is relatively not volatile and its concentration decrease is about $10 \%$.

Chromium is much more volatile than copper; however, its volatility is relatively limited for pyrolysis at $5^{\circ} \mathrm{C} / \mathrm{min}$ heating rate in comparison to that at $20^{\circ} \mathrm{C} / \mathrm{min}$. The maximum decrease of chromium concentration depending on the experimental conditions is about $18 \%$.

Arsenic volatility is higher than both copper and chromium volatilities whatever the heating rate. The arsenic concentration in the pyrolysis solid product decreases markedly with temperature. This is particularly observed for temperature higher than $320^{\circ} \mathrm{C}$. The arsenic concentration decrease is around $16 \%$ at $200^{\circ} \mathrm{C}$, up to $33 \%$ at $400^{\circ} \mathrm{C}$.

In the case of CCA-treated wood, the copper concentration in pyrolysis solid residues is generally very stable, and the concentration decrease in residues is lower than $9 \%$.

The chromium concentration is relatively stable in pyrolysis residues for the temperatures considered. This is especially true for pyrolysis at $20^{\circ} \mathrm{C} / \mathrm{min}$ heating rate, where the concentration decrease is less than $6 \%$. At $5^{\circ} \mathrm{C} / \mathrm{min}$ heating rate, the chromium concentration decrease is around $10 \%$.

The stability of arsenic in this case is relatively higher than in the case of wood waste pyrolysis. The arsenic volatility at $5^{\circ} \mathrm{C} / \mathrm{min}$ is less than at $20^{\circ} \mathrm{C} / \mathrm{min}$. In general, the arsenic concentration decrease in residues of pyrolysed CCA-treated wood is less than $16 \%$.

\subsection{Specific surface area evolution}

The variations of the specific surface area of pyrolysis residues with temperature are presented in Fig. 5, at different heating rates, and for both CCAtreated wood and waste wood. the specific surface areas of initial wood waste and CCA-treated wood samples are $0.7 \mathrm{~m}^{2} / \mathrm{g}$ and $0.8 \mathrm{~m}^{2} / \mathrm{g}$, respectively.

The BET analysis shows that the specific surface area of pyrolysis residues increases with temperature in comparison with that of non-pyrolysed waste but with different level, for every case. So, the specific surface area of the residue is higher than that of the initial wood 
sample (in both cases), and the more the heating rate the more the increase of specific surface area. At $5^{\circ} \mathrm{C} / \mathrm{min}$ heating rate, the specific surface area is moderate and is around of $10 \mathrm{~m}^{2} / \mathrm{g}$ for both CCA-treated wood and

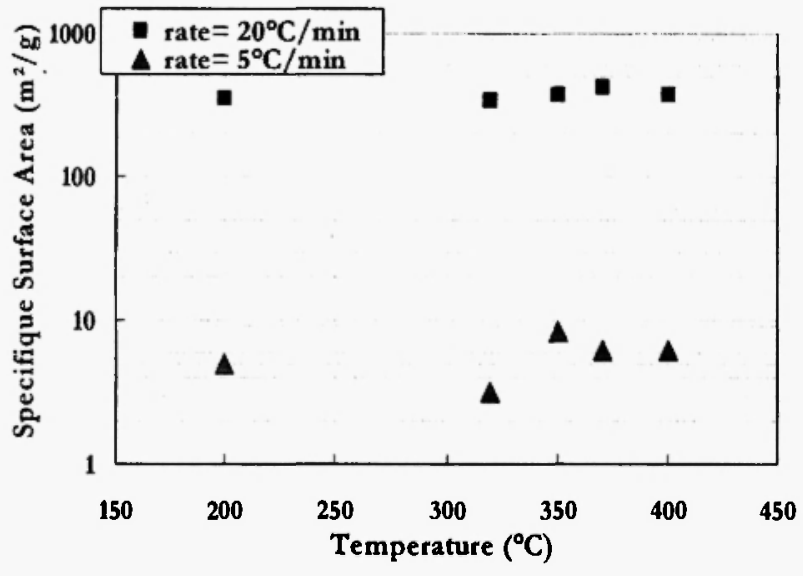

(a) waste wood residues. At $20^{\circ} \mathrm{C} / \mathrm{min}$ heating rate, the specific surface area exceeds $200 \mathrm{~m}^{2} / \mathrm{g}$ for CCA-treated wood residue (except at $200^{\circ} \mathrm{C}$ ) and $320 \mathrm{~m}^{2} / \mathrm{g}$ for wood waste residue.

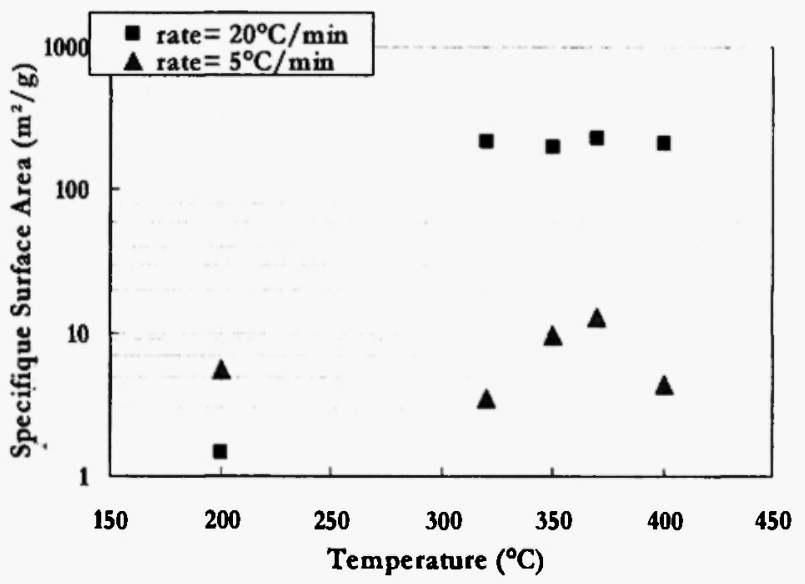

(b)

Fig. 5: Specific surface area of residues pyrolysis vs. temperature at different heating rates.(a) Wood waste; (b) CCAtreated wood.

In the case of CCA-treated wood, the low value of specific area at $200^{\circ} \mathrm{C}$ can be explained by the lower temperature effect on the decomposition of the CCAtreated wood compounds, despite of the long pyrolysis duration at this temperature. This is due to the CCA metals (highly concentrated), which clog the external pores of the initial sample and do not free them at this temperature, oppositely to the case of waste wood where CCA metals' amount is lower and the pore creation in more important.

Finally, this study points out that the most significant effect of the pyrolysis is to generate a residue with a high specific area, and the higher the heating rate the higher the specific surface area, due to the creation of pores.

\section{DISCUSSION}

The evolution of the heavy metal amounts at the pyrolysis residue surface indicates that several phenomena of metal concentrations take place in the surface. The CCA metals initially vaporize and concentred at the residue surface by condensation and nucleation growth an agglomeration.

The higher stability of CCA metals in the case of the CCA treated wood is due to the higher initial CCA metal concentrations, which also promotes the agglomeration of CCA metals /5/.

The increase in the specific surface area during pyrolysis can be explained by the higher initial organic content of waste samples. The resulting effect of the decomposition of organic matter content in the waste samples is the release of the existing pores and the generation of new one. Moreover, the CCA metal leaves the pores progressively by vaporization. The difference observed between values of specific surface area as function of heating rate is probably related to the metal concentration at the residue surfaces. 


\section{CONCLUSION}

Experimental results of the pyrolysis of CCA wood waste have been presented. Two different pyrolysis heating rates have been used in order to compare the effect of the heating rate on the characteristics of charcoal during pyrolysis at low temperature $\left(400^{\circ} \mathrm{C}\right)$.

The main result pointed out from the environmental scanning electronic microscopy is that the CCA metals are concentred at the charcoal surface. This result can be explained by the release of CCA metals during decomposition of organics and evaporation of water content from wood pores. The amounts of the CCA metals increase with temperatures notably up to $320^{\circ} \mathrm{C}$.

Finally, in this study, the pyrolysis of treated wood waste is used to generate reactive charcoal with higher specific surface area (up to $200 \mathrm{~m}^{2} / \mathrm{g}$ ) by the release of the existing pores and the generation of new one during the decomposition of organic mater and the progressive vaporization of the CCA metals from the pores.

Since the treated wood waste could be used for the production of materials (charcoal and CCA metal agglomerates) from waste wood, the approach developed in this paper is a promising one for the valorisation of wood waste as useful material in addition to the standard use for the production of energy.

\section{ACKNOWLEDGMENTS}

This research is supported by Thermya Company, and by Region Aquitaine in France.

\section{REFERENCES}

1. J. Zandersons, A. Zhurinsh, G. Dobele, B. Spince, A. Tardenaka and J. Rizhikovs: Thermal Science, 10 (3), 27-38 (2006).

2. L. Helsen, E. Van den Bulck and J.S. Hery: Waste Manag., 185, 71- 578 (1998).

3. L. Helsen, E. Van den Bulck, M. K. Van Bael and J. Mullens: J. Anal. Appl. Pyrolysis, 68-69, 613633 (2003).

4. L. Helsen and E. Van den Bulck, Environ. Pollut., 134, 301-314 (2005).

5. L. Heslen and A. Hacala: J.Hazard. Mater., B137, 1438-1452 (2006).

6. L. Helsen and E. Van den Bulck: Holzforschung, 52, 607-614 (1998).

7. T. Hata, P.M. Bronsveld, T. Vystavel, B.J. Kooi, J.Th.M. De Hosson, T. Kakitani, A. Otono and Y. Imamura: J. Anal. Appl. Pyrolysis., 68-69, 635643 (2003).

8. www.thermya.com. Thermya Company website, France.

9. L. Helsen: Low-temperature pyrolysis of chromated copper arsenate (CCA) treated wood waste, PhD. Thesis, Catholic University of Leuven, Belgium, (2000).

10. L. Helsen, E. Van den Bulck, S. Mullens and J. Mullens: J. Anal. Appl. Pyrolysis., 52, 65-86 (1999).

11. T. Hirata, M. Inoue and Y. Fukui: Wood Sci. Technol, 27(1), 35-47 (1993).

12. A. K. Kercher and D. C. Nagle: Wood Sci. Technol., 35(4), 325-341 (2001). 